\title{
DIREITO NATURAL E PROPRIEDADE EM JEAN BODIN ${ }^{1}$
}

Alberto Ribeiro G. de Barros ${ }^{2}$

- RESUMO: Este artigo pretende discutir os conceitos de direito natural e propriedade no Iuri universi distributio (1578) e as suas conseqüências políticas no $M e-$ thodus ad facilem historiarum cognitionem (1566) e no Les Six Livres de la République (1576), de Jean Bodin.

- PALAVRAS-CHAVE: Jean Bodin, direito natural, propriedade, soberania.

Bodin faz poucas referências ao direito natural em sua obra. A mais clara, em apenas algumas linhas, encontra-se no Iuris universi distributio (Bodin, 1951), texto publicado em 1578, como um apêndice ao comentário do glosador Azo sobre o Código de Justiniano, no formato de um grande diagrama: seis páginas, $40 \mathrm{~cm} \times 180 \mathrm{~cm}$, com rubricas em divisões sucessivas, sem descrições ou quaisquer explicações. A intenção parece ser apresentar um quadro sinóptico das instituições jurídicas para que fosse possível a rápida memorização dos princípios mais gerais do direito. Apenas na segunda edição, em 1580, as rubricas ganham definições com alguns comentários, às vezes, seguidos de exemplos e de citações (idem, pp.71-80). O texto recebe também uma carta dedicatória, na qual Bodin justifica seu silêncio em relação à arte jurídica:

Embora desejasse sinceramente satisfazer aqueles que têm se queixado do meu silêncio sobre a disposição da arte jurídica, tinha decidido não divulgar o que

\footnotetext{
1 Texto apresentado na III Jornada de Direito Natural, realizada em Curitiba, na UFPR, em junho de 2004.

2 Professor Assistente-Doutor no Departamento de Filosofia da USP.
} 
de mim era solicitado, antes de ter recuperado toda força do direito e da equidade. Isso só foi possível depois de ter coletado e comparado, com habilidade, as decisões jurídicas dispersas numa infinidade de tratados e as melhores leis dos mais ilustres povos, que possuem a ciência do governo da República, e reunido tudo num só corpo. (idem, p.71)

Desde a década de sessenta, convencido de que a arte jurídica não poderia limitar-se somente à recuperação e reordenação do direito romano, como pretendiam seus contemporâneos, Bodin dedica-se a reunir as leis das principais Repúblicas, classificá-las e compará-las, a fim de encontrar o que há de comum entre elas. O resultado desse amplo processo comparativo é apresentado como o direito universal, conjunto de princípios jurídicos comuns a todos os povos e, por isso, de validade e de aplicação universal.

Contrariando aqueles que defendiam a impossibilidade de tratar o direito de maneira sistemática, porque lidava com objetos particulares e, principalmente, porque era mutável, distinto conforme o lugar e o tempo, Bodin pretende, inspirado no projeto ciceroniano de jus in artem redigere (De oratore, I, 42), expor esse direito universal numa ordem simples, clara e racional, para que "os mestres de outras artes não se vangloriassem mais com a vergonha dos juristas de não ter o direito compreendido numa arte" (Bodin, 1951, p.71).

Bodin inicia sua exposição com a definição de jurisprudência, termo utilizado para designar o saber jurídico, como "a arte de atribuir a cada um o que lhe é devido, para manter a sociedade humana" (idem, p.72). Dos três preceitos tradicionais do direito romano - viver honestamente, não lesar a outrem, dar a cada um o que é seu (Digesto, 1,1,12; Institutas, 1,1,3) - retém apenas o último, indicando que se trata de um saber que não pretende tornar os homens moralmente virtuosos, prescrevendo-lhes condutas, mas apenas fixar e manter a correta proporção entre os bens ou outras vantagens partilhadas entre eles. O objetivo dessa disciplina pela qual se conhece o justo é promover a ordem social por meio da correta distribuição dos bens entre os membros de uma comunidade.

Sua definição está assim ligada a uma longa tradição, que remonta ao significado dado pelos antigos gregos ao termo dike, para designar o cumprimento da justiça. Na linguagem processual da Polis, o juiz repartia dike com sua sentença e as partes contenciosas davam e recebiam dike ao cumprir essa sentença (Jaeger, 1986, pp.91-3). O mesmo sentido pode ser encontrado na análise aristotélica da coisa justa (to díkaión), ou seja, o estabelecimento da justiça por meio da sentença do juiz (dikastês), que atribui a cada um o que lhe é devido. Ao tratar da virtude da justiça (dikaiosyne), Aristóteles distingue a arte que se relaciona com a virtude no indivíduo, que lhe prescreve condutas a fim de torná-lo um homem justo (díkaios), daquela que se relaciona com o estabelecimento da coisa justa (to dikaión): a 
justiça particular que visa determinar o que pertence a cada um numa comunidade política (Ética a Nicômaco, V, 1129a-1134a). Esse princípio foi posteriormente fixado na cultura jurídica ocidental pela fórmula de Ulpiano: "Justiça é a vontade constante de atribuir a cada um o seu direito" (Institutas 1,1; cf. Cícero, De officiis I, 20-41; De re publica III, XIV, 22; Agostinho, O livre-arbítrio, III, 13,27; A cidade de deus, XIX, 21; Tomás de Aquino, Suma teológica II, II, questão LVIII). Este parece ser o sentido que Bodin confere à jurisprudência como a arte do justo.

Em seguida, Bodin define o direito como "um raio de luz dado aos homens pela bondade e previdência divina, para a utilidade da sociedade humana" (Bodin, 1951, p.72), reforçando a imagem, já apresentada na carta dedicatória, do direito como uma semente inserida na alma humana por Deus a fim de garantir a existência da vida social e que germina com o desenvolvimento da razão (idem, p.71). Essa definição também se filia a uma antiga tradição que concebe o direito como uma espécie de luz divina enviada para inspirar a consciência dos homens e tornar possível a vida em sociedade (cf. Platão, Protágoras 320e-322d; Cícero, De Legibus I, 22-26; Agostinho, A Cidade de Deus, XIX, 21; Tomás de Aquino, Suma Teológica II, II, questão LVII, art.1).

A preferência pela divisão dicotômica leva Bodin a repartir o direito em natural e humano, abandonando a classificação usual de Ulpiano em natural, das gentes e civil (Institutas 1,2). Sua intenção é claramente se colocar na trilha dos filósofos e juristas da Antigüidade:

Assim, Aristóteles, no livro V da Ética a Nicômaco, e Platão, no segundo livro das Leis, repartem to dikaión (a coisa justa) em physikón (segundo a natureza) e nomikón (segundo a lei), divisão que é seguida por Paulo no penúltimo fragmento sobre a Justiça. (Bodin, 1951, p. 72)

Se acreditarmos no testemunho de Aristóteles, a distinção entre um justo fundamentado na physis e aquele criado a partir do nómos era um lugar-comum reconhecido por seus antecessores como um meio de levar o oponente a cair num paradoxo, porque os termos natureza e convenção eram normalmente apresentados como contrários (cf. Aristóteles, Organon VI, 12, 173a). Sem condições historiográficas de determinar o início dessa oposição, ela pode ser observada, como aponta Bodin, nos diálogos platônicos. De um lado, a tese convencionalista de que o justo não é um dado natural nem tira seu valor e sua força da natureza, pois, se o direito estivesse fundamentado na natureza, ele seria o mesmo para todos os povos e em todos os momentos da história. Ao contrário, ele varia de nação a nação; na mesma nação de uma época a outra; e na mesma época segundo as categorias de cidadãos. Logo, seria preciso reconhecer que o direito sustenta-se 
numa opinião mutável; que os homens obedecem unicamente por temor das sanções; e que as nações, como os indivíduos, seguem sempre a regra do interesse, o único real fundamento do direito (cf. Platão, Leis, X, 889e890a; Górgias, 483b-484 a; República, 338c-339a; 358e-359c). De outro lado, a defesa socrática da existência de uma justiça que não deriva de acordos nem das opiniões humanas, mas que tem seu fundamento na natureza. $\mathrm{O}$ naturalmente justo é identificado por Platão com a própria idéia de justiça, definida tanto como virtude individual que conduz o homem à perfeição moral, à medida que ordena corretamente as partes da sua alma, quanto como virtude social que possibilita a harmonia da cidade, pois atribui a cada um o seu correto lugar e o encargo para o qual a natureza melhor o capacitou (cf. República 433a-b; 443d; 444d-e). A justiça exige que a cada parte seja assinalada a função que possa desempenhar melhor para o bem do todo. Na cidade ideal, o filósofo será o responsável por instaurar a justiça e, por conseguinte, o melhor regime, mantendo-o a partir da ordem natural que contemplou no mundo inteligível, já que é o único capaz de identificar o que é conforme a natureza (cf. República 484a - 492a).

Aristóteles também contrapõe o justo natural ao legal, mas a partir da ordem política. Ambos fazem parte daquela justiça que depende da lei da cidade (Ética a Nicômaco, V, 6, 1134a). A diferença está que o justo natural encontra-se em todas as partes, tem a mesma força e o mesmo valor onde quer que seja, independentemente do que pensam os homens, enquanto 0 justo legal tem seu fundamento na vontade humana que escolhe uma entre as diversas possibilidades apresentadas, que deixa de ser indiferente para se converter numa prescrição. Assim, o justo natural possui uma razão de validade que não depende do parecer humano e representa, desde a origem, a única possibilidade de solução, sendo anterior a qualquer intervenção humana e tendo seu conteúdo fundamentado na própria natureza das coisas. No entanto, segundo Aristóteles, isso não implica que ele seja totalmente imutável, pois a invariabilidade é reservada ao domínio dos deuses: o justo natural não é como o fogo, que brilha igualmente em todo lugar. A partir do momento em que se vincula à atividade humana - e o estabelecimento do justo está necessariamente ligado ao mundo humano, portanto, das realidades contingentes - torna-se também sujeito às mudanças. Porém, sua variação é bem menor do que o justo legal: enquanto este sofre mudanças freqüentes, porque tem seu fundamento na vontade do homem, aquele só a experimenta de maneira excepcional, revelando sempre uma maior generalidade e permanência (Ética a Nicômaco V, 6, 1134b-1135a).

Embora Platão e Aristóteles sejam citados como fonte de inspiração, Bodin parece afastar-se dessa tradição, quando afirma que "o direito natural está inserido em cada um de nós desde a origem da espécie, e por isto é sempre eqüitativo e bom" (Bodin, 1951, p.72). Ao reconhecer no interior do ho- 
mem uma inclinação natural para identificar o certo, um tipo de sentimento inato do justo, parece seguir muito mais as concepções estóicas de Cícero.

No De Legibus, Cícero defende a existência, além de um direito civil posto pela vontade humana, de um direito que tem sua origem e fundamento na natureza:

Entre todas as questões debatidas pelos sábios, certamente a mais importante é aquela que consiste na inteligibilidade dessa verdade: somos nascidos para a justiça e o direito se fundamenta, não sobre a opinião, mas sobre a própria natureza. (De legibus, I, 28)

Essa natureza, no entanto, não é mais aquela da doutrina platônica ou aristotélica, e sim a natureza humana: "Para explicar a natureza do direito, é preciso ir descobri-la na natureza do homem" (idem, I, 17). Por ser a natureza humana essencialmente racional, o meio através do qual o homem tem acesso ao fundamento do direito, só poder ser a razão. Marca distintiva de sua natureza, ela possibilita ao homem identificar o justo, o que é eqüitativo e bom, e então aplicá-lo nas suas relações sociais.

É claro que o contato de Cícero com as idéias estóicas é determinante na elaboração dessa concepção. O materialismo estóico coloca entre os seres vivos um elemento dinâmico - o logos - com força capaz de reuni-los, dando-lhes a coesão necessária para se tornarem um conjunto. Esse elemento, responsável pela produção e organização do mundo, é considerado uma força onipresente, hegemônica e estável que engendra os corpos, os desenvolve e os organiza. Em todos os seres há uma parcela de logos, que está presente em estado puro somente entre os deuses e na alma humana. Por isso, o homem ocuparia um lugar especial entre os seres. Se a finalidade de todo ser é viver segundo sua natureza e o específico do homem é a racionalidade, o fim do homem só poder ser viver racionalmente. Como ser racional, ele deve reconhecer esse princípio ordenador de sua existência e aplicá-lo na sua conduta, pois é o único capaz de conduzi-lo à perfeição. As conseqüências para a ação humana parecem claras: a regra da natureza dita as regras da conduta; a sabedoria consiste em harmonizar-se com o logos; a virtude está em viver de acordo com esse princípio, decretado de forma imperativa na razão de cada ser humano.

Na sua filiação eclética, Cícero herda do estoicismo essa crença num universo racionalmente ordenado, na presença inata de uma parcela do logos em todos os homens, que determina a essência e o fim para o qual cada ser está direcionado, e na consubstancialidade da razão com a alma humana (idem, I, 18). Mas, no seu pensamento, a conformidade não é mais entre uma razão particular com o lógos universal, uma ordem anterior e exterior ao homem. Há um enfraquecimento da idéia de que o curso do universo for- 
nece ao homem sua lei. A alma humana ganha uma certa autonomia e passa a considerar a si mesma, não a ordem cósmica, na ordenação de suas ações. O homem estabelece a sua lei a partir da inquirição interna do seu ser, opondo-se muitas vezes às leis de outros seres naturais. É a sua escolha que faz o direito e não o mero adaptar-se a uma ordem externa. Dado o caráter racional da alma humana, o homem carrega um sentimento inato do justo que deve estar na origem e no fundamento do direito (idem, I, 15).

Há sem dúvida uma clara diferença entre a concepção de Cícero e a dos antigos gregos: o direito natural deixa de ser uma determinação do juiz ou do legislador da cidade, para ser um sentimento inato conhecido pela inquirição das inclinações internas de cada um, que a razão atualiza a cada situação. O pensamento ciceroniano marca o início de uma nova fase do jusnaturalismo clássico, na qual estão presentes os mesmos temas - sociabilidade natural, anterioridade e superioridade do justo natural sobre o convencional etc. - mas com uma perspectiva mais moral e antropológica.

O problema é que Bodin não parece ter percebido essa diferença, acreditando talvez na afirmação de Cícero segundo a qual o que separava Platão, Aristóteles e os estóicos eram apenas as palavras, uma vez que todos tratavam essencialmente das mesmas coisas (idem, I, 12). O próprio Cícero parece não se dar conta de que, na verdade, está tratando de coisas diferentes com as mesmas palavras. Equívoco herdado por Bodin, quando toma certas definições jurídicas, sem considerar as diferentes inspirações nelas contidas, misturando tradições nem sempre compatíveis. Como boa parte de seus contemporâneos, apropria-se de idéias das mais distintas procedências, combinando-as e adaptando-as ao seu interesse, sem atentar para possíveis contradições entre elas.

O conteúdo que Bodin atribui ao direito natural - "a religião no que se refere a Deus, a piedade para com os semelhantes, o reconhecimento aos que merecem, a vingança contra os ímpios, a justiça" (Bodin, 1951, p.72) o aproxima realmente de Cícero, que também sustenta a presença de uma força congênita que desperta no homem noções como a religião, a piedade, o reconhecimento, o desejo em ver os culpados castigados, o respeito e a verdade (cf. De legibus, I, 15). Mas, nos comentários que seguem sua definição, nega a participação dos animais, que é defendida por Cícero, a partir da crença na existência de um direito comum a todo ser vivo (cf. Cícero. De finibus, III, 19, 62-65). Muito mais próximo daqueles juristas romanos que definem o direito natural como um direito ideal praticado por todos os homens por causa de seu fundamento racional (cf. Institutas 1,1,2; Digesto $1,1,2$ ), identificando-o com o jus gentium, no sentido mais amplo de um direito próprio ao homem, enquanto ser racional, um direito estabelecido pela razão natural que é igualmente observado entre todos os povos (cf. Digesto $1,1,1,3 ; 1,1,9)$, Bodin afirma que o direito natural é exclusivo dos ho- 
mens, uma vez que qualquer relação jurídica só pode ser estabelecida entre seres racionais.

Já o direito humano é definido como "aquele que é estabelecido para a utilidade dos homens, conforme a natureza" (Bodin, 1951, p. 72). Não há, na verdade, uma especificação da natureza à qual Bodin está se referindo. Mas, dada sua definição de direito natural, essa natureza parece ser a natureza racional do homem: se o direito humano depende de uma vontade para impor uma determinação útil, esta vontade deve ser guiada pela razão. A distinção entre direito natural e direito humano parece estar fundamentada em dois critérios: o modo pelo qual são conhecidos e a valoração de suas ações. Enquanto o direito natural é um sentimento inato do justo, conhecido por meio da razão, que estabelece aquilo que é eqüitativo e bom, o direito humano é sempre o resultado de uma declaração expressa da vontade humana, necessita de uma promulgação, já que se sustenta numa convenção e determina aquilo que é útil. De qualquer modo, a natureza racional do homem permanece como uma espécie de axioma, a partir do qual o direito humano deve ser deduzido, tendo em vista determinadas circunstâncias. Aliás, é a presença dessa razão natural que explicaria as semelhanças entre os diversos sistemas legislativos, legitimando o procedimento comparativo na busca de um direito universal.

Essa crença na equivalência entre razão e natureza na origem do direito encontra-se também em juristas contemporâneos de Bodin. Para François Connan, por exemplo, o fundamento de toda forma de direito é a natureza que, sendo no homem de substância racional, faz com que a fonte do direito só possa ser a reta razão (cf. Connan, Commentarii, I,I, folha 2). Por isso, o conteúdo do direito não exprime o justo, segundo uma opinião, mutável no tempo, mas o que é verdadeiro e honesto, inscrito na razão natural (idem, I,II, folha 5). A mesma convicção de que a natureza humana é a fonte primeira do direito, conferindo-lhe seu caráter racional, pode ser observada em Jean Coras, para quem a constatação da diversidade de leis e instituições entre os povos e sua mutabilidade histórica no mesmo povo não deve obscurecer o real fundamento do direito: a eqüidade natural, princípio supremo e eterno, impresso na razão humana, que estabelece o honesto e o justo (Coras, De iure civili in artem redigendo, p.59). Hugo Doneau chega até mesmo a defender a existência de direitos fixados para sempre, por serem inerentes à natureza imutável do homem. Afirma que alguns pertencem a cada um de nós independentemente dos objetos exteriores, como a vida, a integridade física, a liberdade, a honra (Doneau, De jure civili commentaria, I,1, §3); outros são exercidos sobre as coisas exteriores que pertencem à pessoa, como a propriedade e os direitos sobre os bens de outrem e os direitos oriundos das obrigações. Mas todos esses direitos, mesmo 
aqueles criados pela vontade humana em função de suas necessidades, têm seu fundamento na natureza racional do homem (idem, I,7, §8-10).

Não se está assim tão longe das concepções dos jusnaturalistas do século XVII, como Grotius, Pufendorf ou mesmo Locke. Apoiados nessa tradição que estabelecia a natureza racional do homem como fundamento do direito, Bodin e seus contemporâneos esboçam uma nova noção de direito natural, contribuindo de maneira decisiva na formação do pensamento jurídico moderno.

A noção de propriedade aparece na segunda parte do Iuris universi distributio, que se refere à matéria do direito, isto é, à área de aplicação em torno da qual se encontram as questões referentes ao direito: as pessoas, as coisas e os fatos - reproduzindo a divisão usual do direito romano (Institutas 1,3). As concepções de Bodin praticamente em nada diferem daquelas presentes na compilação de Justiniano e comentadas pelos juristas medievais: a mesma distinção entre posse e propriedade, os tipos de posse, as formas de aquisição e de alienação da propriedade etc (Bodin, 1951, pp.76-7).

Alguns glosadores e bartolistas já haviam traçado uma clara distinção entre a propriedade privada dos súditos (proprietas) e o poder de julgar e de dizer o direito (jurisdictio) do imperador, que era senhor (dominus) somente no que se referia a proteção e jurisdição, não incluindo aí os bens de seus governados. Bodin parece retomar essa distinção, aplicando-a a sua teoria, ao sustentar que a soberania não implica a posse dos bens dos súditos: "ao dizer que os príncipes são senhores de tudo, entende-se o direito senhorial e a justiça soberana, permanecendo necessariamente cada um com a posse e propriedade dos seus bens" (idem, p.223). Se no Iuris universi distributio, dado seu caráter conciso, pouca coisa é dita, em outros textos, Bodin extrai conseqüências políticas relevantes de sua noção de propriedade. No $\mathrm{Me}$ thodus ad facilem historiarum cognitionem (Bodin, 1951a) ao discutir a relação do soberano com as leis constitucionais, combate veementemente a tese de Jason de Mayno, um dos conselheiros de Luís XII, segundo a qual o rei era o detentor de todos os direitos, inclusive o de se apossar das propriedades de seus súditos, já que era o legítimo proprietário de todas as coisas do reino. Utilizando o argumento de Sêneca de que o poder público pertence aos reis e a propriedade, aos particulares (cf. Sêneca, De Beneficiis VII, 4), repudia essa idéia, considerando-a uma das mais perniciosas à República (Bodin, 1951a, pp.222-3).

Em Les Six Livres de la République (Bodin, 1986), a discussão é mais abrangente. Ao comentar como os príncipes estão sujeitos às leis divinas e naturais, afirma que elas proíbem ao soberano, mesmo detendo um poder absoluto, atentar contra a propriedade de seus súditos: "Não se pode isentar nem o papa nem o imperador, como fazem aqueles aduladores que defendem o direito papal e imperial de tomar os bens de seus súditos sem um 
causa; vários doutores, e mesmo alguns canonistas, abominam essa opinião, considerando-a contrária à lei de Deus. Ela não pode estar sustentada no poder absoluto; melhor seria fundamentá-la na força e nas armas, que é o direito do mais forte e dos ladrões, visto que o poder absoluto não é outra coisa senão a derrogação das leis civis, como já foi demonstrado, e que não pode atentar às leis de Deus, que anunciou por meio de suas leis que não é lícito tomar nem mesmo cobiçar o bem do outro" (Bodin, 1986, I, p.221).

O soberano possui, de fato, um poder absoluto, isto é, superior, independente, incondicional e ilimitado, pois qualquer submissão, restrição, obrigação ou limitação é incompatível com a própria idéia de soberania. Numa sociedade política, Bodin entende que ter poder absoluto significa estar acima das leis civis: "Aquele que melhor compreendeu o que é poder absoluto disse que não é outra coisa senão a possibilidade de revogar o direito positivo" (idem, I, p.193). O caráter absoluto do poder soberano manifesta-se principalmente no direito de criar, de corrigir e de anular as leis civis de acordo com a vontade do seu detentor: "É preciso que os soberanos possam dar a lei aos súditos e anular ou revogar as leis inúteis para fazer outras; o que não pode ser feito por aquele que está submetido às leis ou por aquele que está sob o comando de outrem" (idem, I, p.191). Como a lei imposta por Deus à natureza tem seu fundamento na vontade divina, assim também a lei outorgada pelo soberano, embora possa estar fundamentada em boas razões, retira sua autoridade da livre vontade do soberano. O detentor da soberania deve estar livre diante das leis que estabeleceu e das que foram estabelecidas pelos seus predecessores, não sendo obrigado a cumpri-las contra sua vontade. Primeiro, porque ninguém pode se obrigar a si mesmo. Depois, porque se fosse obrigado a cumprir as leis que foram estabelecidas antes dele, seu poder não seria absoluto. Ele deve ainda estar livre diante do direito das gentes, quando for perverso ou malévolo, e dos costumes, que só se tornam efetivos pela vontade do soberano, que autoriza sua existência (idem, I, p.228).

O direito de legislar é considerado por Bodin o primeiro e mais importante direito da soberania, porque a partir dele todos os demais são definidos. Os direitos de declarar a guerra e tratar a paz, instituir os principais oficiais, estabelecer o peso e o valor das moedas, impor taxas e impostos ou isenções, de ser a última palavra em qualquer assunto, outorgar vantagens, exceções e imunidades a quem desejar são decorrentes desse direito de dar a lei em geral (idem, I, p.309).

Mas a posse do poder absoluto não dá ao soberano o direito de tomar arbitrariamente os bens de seus súditos. Qualquer intervenção, sem justa causa, na propriedade privada, seja na forma de confisco, seja por meio do aumento de impostos, é considerada indevida, porque ultrapassa os limites de 
ação do poder político: "não está no poder de nenhum príncipe do mundo aumentar impostos a seu prazer nem tomar o bem de outrem" (idem, I, p. 201).

Impor ou isentar os súditos de taxas e contribuições é um dos direitos da soberania, compreendido naquele mais importante e abrangente que é o de legislar. As leis fiscais, como todas as leis positivas, dependem realmente da vontade do soberano: "quanto ao direito de impor aos súditos taxas e impostos ou isentar alguns deles, depende do poder de dar a lei e os privilégios [...] se há necessidade de os impor ou os suprimir, só pode ser feito por aquele que tem o poder soberano" (idem, I, p.334).

No entanto, esse direito não pode ser exercido de maneira discricionária. Se os impostos são um dos meios de que o soberano dispõe para custear as despesas da República, eles só devem ser instituídos quando os outros meios consagrados pela tradição - a renda proveniente do uso do domínio da República; os recursos provenientes das conquistas sobre os inimigos; as doações dos súditos; as pensões pagas pelos aliados; as taxas sobre alguns serviços públicos e sobre o comércio - forem insuficientes ou houver grande necessidade (idem, VI, pp.35-62). Nestes casos, a criação de impostos depende ainda do consentimento dos súditos, que devem autorizar a tributação.

O confisco da propriedade, sem o consentimento, só é justificado em casos de extrema urgência, quando há um perigo comprovado que coloque em risco a existência da República: "Se a necessidade é urgente, o príncipe não deve esperar a assembléia dos estados nem o consentimento do povo, cuja salvação depende da previsão e diligência de um sábio príncipe" (idem, I, p.201). Em tais casos, como na justificativa para o descumprimento dos contratos, o público deve ter prioridade sobre os interesses particulares e o soberano, como legítimo representante e defensor do bem público, não necessita da autorização dos seus súditos para utilizar o patrimônio deles: "A razão natural quer que o público seja preferido em relação ao particular e que os súditos abram mão, não somente de suas injúrias e vinganças, mas também de seus bens, para a salvação da República" (idem, I, p.222). Somente nesses casos excepcionais, o soberano pode tomar os bens dos súditos sem seu consentimento: "Uma vez que a proteção e defesa dos particulares dependem da conservação do público, é preciso empregar este meio; as taxas e as imposições sobre os súditos são então muito justas, pois não há nada mais justo do que o necessário" (idem, VI, p.67).

Enfim, com exceção dessas causas consideradas justas e razoáveis, quando o público encontra-se em perigo, a posse da soberania não autoriza a intervenção na propriedade privada: "Com exceção das causas que tratei, o príncipe não pode tomar nem doar o bem de outro, sem consentimento do seu proprietário; e em todos os dons, graças, privilégios e atos do príncipe sempre deve constar a cláusula salvo o direito de outrem, que deve ser subentendida, quando não estiver expressa" (idem, I, p.223). 
A propriedade privada é assim concebida como um direito inviolável, protegida pelas leis divinas e naturais: "Se o príncipe soberano não tem poder de infringir as leis naturais, postas por Deus, do qual ele é imagem, não poderá também tomar o bem de outrem, sem uma causa que seja justa e razoável" (idem, I, p.222).

Apesar de sua constante presença no texto bodiniano, não se encontra uma clara definição de lei divina. Algumas vezes é apresentada como uma lei eterna e imutável, que manifesta ao mesmo tempo a sabedoria e a vontade de Deus, responsável pela existência e conservação de todas as coisas, segundo um esquema rigorosamente hierárquico, no qual cada ser ocupa um lugar determinado. Quase sempre associada à lei revelada nas Sagradas Escrituras, mais especificamente, à lei mosaica, ela aparece como a expressão da vontade de Deus. Considerada modelo a partir do qual o soberano deve se inspirar para criar a lei civil, a lei divina intervém em diversos aspectos da vida social e política. ${ }^{3}$ Como todo súdito de Deus, o soberano deve submeter-se à lei divina. Se ele está isento das leis positivas, que provêm de sua vontade, o mesmo não acontece diante da lei divina, expressão da vontade de Deus, que ultrapassa e sustenta seu poder: "todos os príncipes da Terra estão submetidos à lei divina e não têm poder de contrariá-la, se não querem ser culpados de crime de lesa majestade, fazendo guerra contra Deus" (idem, I, pp.192-3).

Não se encontra também uma clara definição de lei natural. Ela aparece quase sempre ligada à lei divina, às vezes pela conjunção ou, às vezes pela conjunção $e$, marcando ora alternância, ora equivalência. Tomadas praticamente como sinônimas, elas parecem se distinguir apenas pela maneira de se manifestar: enquanto a lei divina é conhecida por meio da revelação, a lei natural se impõe à razão pela eqüidade que carrega. Ambas expressam a vontade de Deus, diante da qual o poder do soberano está submetido. Assim, a concepção bodiniana de lei natural, quase sempre associada à lei divina, como expressão máxima da eqüidade que se impõe à razão humana, parece aproximar-se também da tradição ciceroniana.

No Da Republica, para combater a concepção convencionalista de Carnéades, Cícero defende a existência de uma lei natural, também chamada de divina, eterna e imutável, identificada com a própria razão, que não pode ser contestada, nem derrogada, nem anulada pelo homem, sem que ele se

3 Por exemplo, nas cláusulas dos contratos de casamento, sustentando a autoridade do marido (Bodin, 1986, I, cap.3); na força obrigatória das leis e dos éditos dos príncipes (idem, I, cap.8); na maneira de julgar um tirano (idem, II, cap.4); na extradição e no dever mútuo dos príncipes de se livrar dos criminosos (idem, III, cap.6); na distinção entre uma guerra justa e injusta (idem, V, cap.5); no direito de sucessão (idem, VI, cap.3); na reprovação da ginecocracia (idem, VI, cap.5); etc. 
despoje de seu caráter de ser humano (Da Republica, III, 18). Seu principal argumento, inspirado nos estóicos, está fundado na inquestionável presença dessa lei, marca da divina inteligência, em todas as coisas: todo o universo é governado pelo logos, a mais alta expressão da suprema racionalidade, que dá às coisas estrutura, propósito e função. Identificada com a própria razão divina, estabelece os princípios ordenadores que preservam e conservam tudo que existe. A própria natureza, que em todos os seus níveis está penetrada de racionalidade, existe em função dessa razão. Entre as criaturas da natureza, o homem é o único que a carrega em seu ser. Por isso, ela revela-se diretamente à sua consciência, não tendo necessidade de intérprete ou comentador, impondo-se a todas as nações em todos os tempos e lugares. Assim, as leis humanas devem buscar seu fundamento nessa lei natural, divina e eterna. ${ }^{4}$

Por ser considerada a expressão máxima da eqüidade, as leis divinas e naturais delimitam, segundo Bodin, a ação do soberano, cujo poder absoluto está nitidamente restrito ao âmbito das leis civis: "O poder absoluto dos príncipes e senhores soberanos não se estende de forma alguma às leis de Deus e da natureza" (Bodin, 1986, I, p.193)

Ora, parece difícil sustentar, como fazem tantos comentadores, que elas são apenas freios morais, que pesam sobre a consciência do soberano. Além da inviolabilidade da propriedade privada, elas exigem o cumprimento dos contratos, obrigando as partes, mesmo que uma delas seja o soberano, a cumprir suas promessas. De fato, elas não são dotadas de eficácia legal, pois não exercem coerção jurídica sobre o detentor da soberania. Entre o soberano e a obediência às leis divinas e naturais não existe um intermediário que possa obrigar o soberano a respeitá-las. Mas, se não exercem constrangimentos jurídicos, não se pode ignorar as conseqüências do seu desprezo: "É verdade que não se encontra príncipe tão mal informado, que tivesse desejado ordenar coisa contrária às leis de Deus e da natureza, pois perderia o título e a honra de príncipe" (idem, III, p.97).

$\mathrm{Na}$ verdade, elas chegam a adquirir um conteúdo concreto, segundo Bodin, quando suas determinações coincidem com as leis humanas: "Como o príncipe soberano não está obrigado pelas leis dos gregos nem de qualquer outro estrangeiro, assim também não está submetido às leis dos romanos ou a suas próprias leis, a não ser que elas estejam de acordo com as leis naturais" (idem, I, p.221). Se qualquer uma de suas normas estiver consagrada na legislação positiva, o soberano deve obedecê-la, pois obriga a to-

4 A mesma concepção é encontrada no De Legibus: "Para fundar o direito, tomemos por origem esta lei suprema que, comum em todos os séculos, nasceu antes que existisse qualquer lei escrita ou que fosse constituída qualquer cidade." (Cícero, De Legibus, I, 19). 
dos, inclusive ao próprio soberano: "É resoluto que todos os príncipes estão sujeitos ao direito natural; uma vez que tais leis são naturais, o príncipe deve publicá-las; e mais ainda quando a lei é justa e útil" (idem, I, p.215).

O soberano está assim submetido às normas do direito natural, que lhe proíbem, entre outras coisas, tomar arbitrariamente a propriedade dos súditos. O direito natural, expresso aqui no direito à propriedade, restringe a ação do soberano. Torna-se um limite concreto ao exercício do poder político. Pode-se concluir que o tão propagado absolutismo de Bodin parece proceder de uma leitura parcial de sua obra.

BARROS, A. R. G. de. Natural right and property in Jean Bodin. Trans/Form/Ação, (São Paulo), v.29(1), 2006, p.31-43.

- ABSTRACT: This article aims to discuss the concepts of natural right and property in Bodin's Iuri distributio universi (1578) and the political consequences of these ideas in Methodus ad facilem historiarum cognitionem (1566) and Les Six Livres de la République (1576).

- KEYWORDS: Jean Bodin, natural right, property, sovereignty.

\section{Referências bibliográficas}

BODIN, Jean. Iuris universi distributio (1580). In: Oeuvres Philosophiques de Jean Bodin. Paris, PUF, 1951.

Les Six Livres de la République (1576). Paris, Fayard, 1986. 6 vols.

Methodus ad facilem historiarum cognitionem (1566). In: Oeuvres Philosophiques de Jean Bodin. Paris, PUF, 1951a.

JAEGER, W. Paidéia. São Paulo: Martins Fontes, 1986.

Artigo recebido em 06/05; aprovado para publicação em 12/05. 